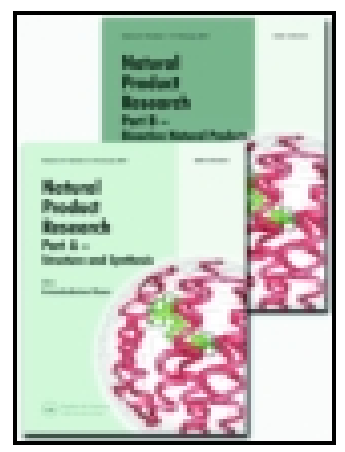

\title{
Natural Product Research
}

Formerly Natural Product Letters

ISSN: 1478-6419 (Print) 1478-6427 (Online) Journal homepage: https://www.tandfonline.com/loi/gnpl20

\section{Phytotoxic metabolites produced by Diaporthe eres involved in cane blight of grapevine in Italy}

\section{Pierlugi Reveglia, Andrea Pacetti, Marco Masi, Alessio Cimmino, Giuseppe Carella, Guido Marchi, Laura Mugnai \& Antonio Evidente}

To cite this article: Pierlugi Reveglia, Andrea Pacetti, Marco Masi, Alessio Cimmino, Giuseppe Carella, Guido Marchi, Laura Mugnai \& Antonio Evidente (2019): Phytotoxic metabolites produced by Diaporthe eres involved in cane blight of grapevine in Italy, Natural Product Research, DOI: 10.1080/14786419.2019.1679133

To link to this article: https://doi.org/10.1080/14786419.2019.1679133

View supplementary material $₫$

曲 Published online: 01 Nov 2019.

Submit your article to this journal $\pi$

Џll Article views: 27

Q View related articles $\longleftarrow$

View Crossmark data $\nearrow$ 


\title{
Phytotoxic metabolites produced by Diaporthe eres involved in cane blight of grapevine in Italy
}

\author{
Pierlugi Reveglia ${ }^{\mathrm{a}}$ (D) Andrea Pacetti ${ }^{\mathrm{b}}$ (D) Marco Masi $^{\mathrm{a}}$ (D), Alessio Cimmino ${ }^{\mathrm{a}}$ (D), \\ Giuseppe Carella ${ }^{\mathrm{b}}$ (D) Guido Marchi ${ }^{\mathrm{b}}$, Laura Mugnai ${ }^{\mathrm{b}}$ (D) and Antonio \\ Evidente $^{\mathrm{a}}$ iD \\ ${ }^{a}$ Dipartimento di Scienze Chimiche, Università di Napoli Federico II, Complesso Universitario

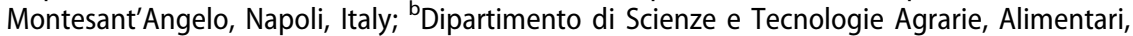 \\ Ambientali e Forestali, Sez. di Patologia Vegetale ed Entomologia, Università di Firenze, Firenze, Italy
}

\begin{abstract}
Grapevine trunk diseases (GTDs) are one of the most serious biotic stresses affecting this important crop. Among them a range of diseases were identified and associated to a plethora of phytopathogenic fungi, including species of Diaporthe. Diaporthe eres was recently identified as one of the species involved in cane blight of grapevine. The ability of a strain of this fungus isolated from infected grapevine plant in Italy to produce in vitro phytotoxic metabolites was investigated. Five phytotoxic metabolites were identified by their physical and spectroscopic properties as 4-hydroxybenzaldehyde, 4-hydroxybenzoic acid, nectriapyrone, $p$-cresol and tyrosol. When tested on grapevine leaf disks and by leaf absorption, 4-hydroxybenzoic acid induced symptoms on both disks and leaves, 4-hydroxybenzaldehyde and $p$-cresol showed, respectively, phytotoxicity on leaf disks and on the leaf absorption bioassay.
\end{abstract}

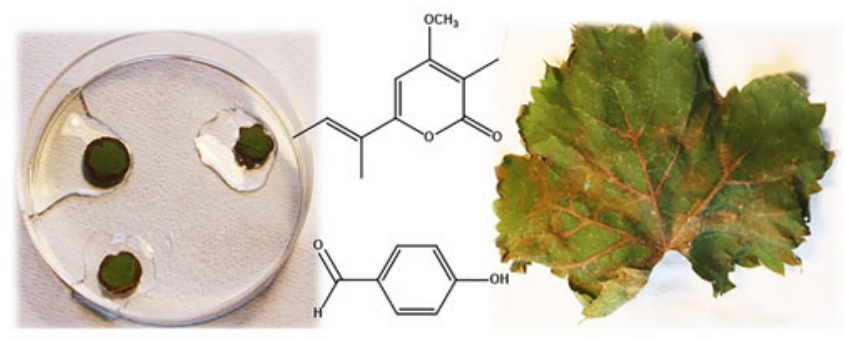

\section{ARTICLE HISTORY}

Received 26 July 2019

Accepted 28 September 2019

\section{KEYWORDS}

Grapevine cane bleach; Diaporthe eres; fungal phytotoxins; 4-

hydroxybenzaldehyde; 4-hydroxybenzoic acid; p-cresol

\section{Introduction}

Grapevine (Vitis vinifera L.) can be affected by many different biotic stresses, including pathogenic fungi that induce severe disease symptoms on different plant organs. The diseases affecting the woody tissues, i.e. trunk and cordons, grapevine trunk diseases 
(GTDs), are among the major threats in grapevine cultivation reducing vineyard longevity and productivity in all the areas where grapevine is cultivated. GTDs are caused by various pathogenic fungi which are able to produce a wide range of toxic metabolites belonging to different classes of naturally occurring compounds (Masi et al. 2018). Species of Diaporthe have also been recently reported as GTDs agents in different regions as in China (Dissanayake et al. 2015), Croatia (Kaliterna et al. 2012), California (Úrbez-Torres et al. 2013), South America (Sessa et al. 2017) and Europe (Guarnaccia et al. 2018; Guerin-Dubrana et al. 2019) . D. eres was one of the most commonly detected species, isolated for the first time in Italy from infected grapevines in Tuscany (Cinelli et al. 2016) showing discoloration of the canes, often surrounded by irregular dark spots and dead sprouts. $D$. eres, was also associated, together to other Diaporthe spp., with wood cankers of fruit and nut crops in northern California (Lawrence et al. 2015).

Fungi belonging to the genus Diaporthe are well known as plant pathogens and as producers of phytotoxins as D. foeniculi (Evidente et al. 1994) and D. gulyae, (Andolfi et al. 2015; Cimmino et al. 2015). D. eres, recently isolated from infected leaves of Hedera helix, also produced 3,4-dihydro-8-hydroxy-3,5-dimethylisocoumarin and tyrosol which together with some isocoumarin analogs were proposed as potential herbicides (Meepagala et al. 2018).

This manuscript reports the isolation and the chemical and biological characterization of the phytotoxic metabolites produced by a strain of $D$. eres isolated in Italy from grapevines showing cane bleach symptoms.

\section{Results and discussion}

The organic extract of the culture filtrates of $D$. eres was purified, by combination of column and TLC as detailed described in the Experimental section, to yield five homogeneous compounds. These latter were identified by TLC analysis carried out in different conditions, in comparison with the corresponding standard and also by cochromatography. Furthermore, their spectroscopic properties (essentially ${ }^{1} \mathrm{H}$ NMR and MS) were very similar to those previously reported for 1 (Avent et al. 1992), for 2 (Venkatasubbaiah et al. 1991; Zhang et al. 2012), for 3 (Kasthuraiah et al. 2004; Passmore et al. 2018) for 4 (Kimura and Tamura 1973; Venkatasubbaiah et al. 1991; Capasso et al. 1992) for 5 (Zhang et al. 2012; Cimmino et al. 2017). For 1 we carried out a complete ${ }^{1} \mathrm{H}$ and ${ }^{13} \mathrm{C}$ NMR study for the first time using $1 \mathrm{D}$ and $2 \mathrm{D}$ NMR experiments (COSY, HSCQ and HMBC) (Figures S1-S5, Supplementary materials) that allowed to unambiguously assign the chemical shifts to all the carbons and the corresponding protons as reported in Table S1 of Supplementary materials, in respect to the data previously reported using only 1 D NMR (Avent et al. 1992).

Nectriapyrone (1), a pentaketide monoterpenoid, was isolated from a Bulgarian strain of Phomopsis foeniculi together with some already known anthracenones. Assayed by tomato leaf-puncture 1 showed only slightly activity, inducing small watery lesions around the inoculated point of the same leaves (Evidente et al. 2011). The phytotoxic activity of $\mathbf{1}$ was also assayed on some other non host plants (Cirsium arvense L., Scop., Sonchus oleraceus L. and Chenopodium album L.) in comparison to its 
dihydro derivative and pestalopyrone. The latter is the main phytotoxic metabolite isolated from the culture filtrates of Pestalotiopsis guepinii, the fungus causing twig blight of hazelnut (Türkkan et al. 2011).

4-Hydroxybenzaldehyde (2) was first reported as phytotoxin produced by Phaeomoniella chlamydospora involved in the esca complex disease of grapevine (Tabacchi et al. 2000) and later from Spencermartinsia viticola, one of the causal agents of grapevine Botryosphaeria dieback in Australia (Reveglia et al. 2018). p-Cresol (3), which has been recently isolated from the culture of Clostridium difficile, a Gram-positive spore-forming anaerobe and a major cause of antibiotic-associated diarrhoea.1 had bacteriostatic activity against microorganisms including Escherichia coli, Klebsiella oxytoca and Bacteroides thetaiotaomicron (Passmore et al. 2018). However, this is the first time that $p$-cresol was detected as a secondary phytotoxic metabolite from a fungus pathogenic for grapevine.

Tyrosol (4), is a toxic compound extracted both from plants (Capasso et al. 1992) and fungi (Masi et al. 2018) including the grapevine pathogenic fungi Lasidiplodia euphorbicola and Lasiodiplodia hormozganensis (Cimmino et al. 2017), Neofusicoccum australe, associated with grapevine cordon and branch dieback (Andolfi et al. 2012) and N. parvum (Evidente et al. 2010). It was also produced, together with some melleins and $p$-hydrobenzaldehyde (2) by Diplodia seriata (syn. Botryosphaeria obtusa), which causes black rot of apple fruit and frogeye leaf spots (Venkatasubbaiah et al. 1991). Tyrosol (4) is toxic to tomato and is a quorum sensing molecule in Candida albicans, controlling growth, morphogenesis, and biofilm formation (Albuquerque and Casadevall 2012).

4-Hydroxybenzoic acid (5) is present in the root exudate of grapevine and other plants (Einhellig and Rasmussen 1978; Guo et al. 2010; Yu and Matsui 1994) and has more recently been reported as one of the metabolites produced by D.gulyae, a fungal species that has been proposed as a mycoherbicide to control the annual weed Carthamus lanatus (Andolfi et al. 2015). 4-Hydroxybenzoic acid (5) is toxic to lettuce seedlings ( $\mathrm{Yu}$ et al. 1994) and inhibits radish and grain sorghum germination and growth (Einhellig and Rasmussen 1978).

Metabolites 1-5 were assayed on grapevine (Vitis vinifera) by the leaf disk bioassay and by the leaf absorption bioassay as fully described in the Experimental part. The observed symptoms included marginal darkening and necrosis of the disk and wilting, reddening of the leaf veins and lamina distortion on the leaves (Figures 2 and 3). In general, for all the compounds in both bioassays, phytotoxicity increased with concentration (range $0.1-1 \mathrm{mg} / \mathrm{mL}$ ). 4-Hydroxybenzoic acid induced the greatest symptoms on both leaf disks and leaves, while 4-hydroxybenzaldehyde and p-cresol showed, respectively, phytotoxicity on leaf disks and leaf absorption bioassay (Table 1).

\section{Experimental}

\subsection{General experimental procedures}

${ }^{1} \mathrm{H}$ and ${ }^{13} \mathrm{C}$ NMR spectra were recorded at 400 or 500 and 100 or $125 \mathrm{MHz}$ in $\mathrm{CDCl}_{3}$ or otherwise noted, on Bruker (Karlsruhe, Germany) and Varian (Palo Alto, CA, USA) instruments. The same solvent was also used as an internal standard. DEPT, COSY-45, 
HSQC, HMBC and experiments (Berger and Braun 2004) were performed using Bruker or Varian microprograms. ESI MS and LC/MS analyses were performed using the LC/MS TOF system AGILENT (Agilent Technologies, Milan, Italy) 6230B, HPLC 1260 Infinity. Analytical and preparative TLCs were carried out on silica gel (Kieselgel 60, $F_{254}, 0.25$ and $0.5 \mathrm{~mm}$ respectively) or on reverse phase (RP-18 $F_{254}, 0.25 \mathrm{~mm}$ ) plates (Merck, Darmstadt, Germany). The spots were visualized by exposure to UV radiation, or by spraying first with $10 \% \mathrm{H}_{2} \mathrm{SO}_{4}$ in $\mathrm{MeOH}$, and then with $5 \%$ phosphomolybdic acid in $\mathrm{EtOH}$, followed by heating at $110^{\circ} \mathrm{C}$ for $10 \mathrm{~min}$. Column chromatography was performed using silica gel (Kieselgel 60, 0.063-0.200 mm) (Merck). The standard samples of tyrosol, $p$-hydroxybenzaldehyde, $p$-hydroxybenzoic acid and $p$-cresol were purchased from Sigma (Milan, Italy). A standard sample of nectriapyrone was obtained from purification of culture filtrates of a Bulgarian strain of Phomopsis foeniculi (syn Diaporthe angelicae) (Evidente et al. 2011).

\subsection{Fungal isolates and culture conditions}

The strain of $D$. eres (CPC 28423) used in this study was obtained from infected grapevine wood of a vineyard in Tuscany and stored in the Culture collection of P.W. Crous, housed at Westerdijk Fungal Biodiversity Institute (CPC), Utrecht, The Netherlands. For phytotoxin production it was inoculated and grown in stationary culture of modified Difco Czapek Dox medium (Benton, MD, USA) with $0.5 \%$ yeast and $0.5 \%$ malt extract (both from Difco, Pittsburgh, PA, USA), for 21 days at $25^{\circ} \mathrm{C}$ in the dark. The mycelium was removed and the liquid cultures were lyophilized prior to the extraction procedure.

\subsection{Extraction and purification D. eres CPC 28423 metabolites}

The culture filtrates $(10 \mathrm{~L})$ of $D$. eres CPC 28423 were reduced under vacuum until they reached $500 \mathrm{~mL}$. The solution was extracted with EtOAc $(3 \times 400 \mathrm{~mL})$. The organic extracts were combined, dried $\left(\mathrm{Na}_{2} \mathrm{SO}_{4}\right)$, and evaporated under reduced pressure. The corresponding residue $(494 \mathrm{mg})$ was purified by silica gel column chromatography, eluted with $\mathrm{CHCl}_{3}-i-\mathrm{PrOH}$ (95:5), yielding seven homogeneous fraction groups. The residue of fraction one (10 mg) was purified by TLC eluted with $\mathrm{CHCl}_{3}-i-\mathrm{PrOH}$ (98:2), resulting in one amorphous solid recognized as nectriapyrone (1, Figure 1, Rf 0.8, $2.2 \mathrm{mg})$. The residue of fraction two $(11.4 \mathrm{mg})$ was purified on silica TLC, eluted with $\mathrm{CHCl}_{3}$-EtOAc (6:4), yielding a brown amorphous solid characterized, 4-hydroxybenzaldehyde (2, Figure 1, Rf 0.4, $0.4 \mathrm{mg}$ ). The residue of fraction four $(25.2 \mathrm{mg}$ ) was further purified by preparative TLC on silica gel, using $\mathrm{CHCl}_{3}-i-\mathrm{PrOH}$ (98:5) as an eluent, affording a viscus yellow oil identified as $p$-cresol (3, Figure 1, Rf $0.8,1.7 \mathrm{mg}$ ) and a white amorphous solid identified as tyrosol (4, Figure 1, Rf 0.7, $5.7 \mathrm{mg}$ ). Finally, from the purification of fraction five $(7.6 \mathrm{mg})$ by reverse phase using $\mathrm{MeOH}-\mathrm{H}_{2} \mathrm{O}(1: 1)$ yielded 4-hydroxybenzoic acid (5, Figure 1, Rf 0.6, $1.5 \mathrm{mg}$ )

Nectriapyrone (1): ${ }^{1} \mathrm{H}$ and ${ }^{13} \mathrm{C}$ NMR spectra were similar to those previously reported (Avent et al. 1992), 1D and 2D ${ }^{1} \mathrm{H}$ and ${ }^{13} \mathrm{C}$ NMR spectra are reported in the 


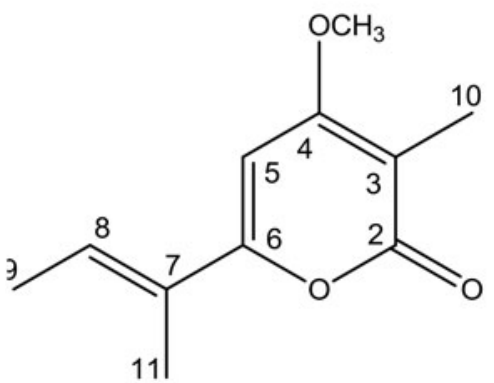

1, Nectriapyrone

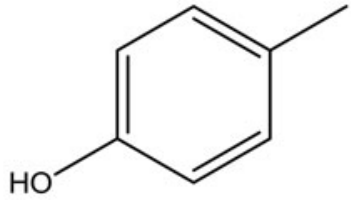

3, p-Cresol<smiles>[R]c1ccc(O)cc1</smiles>

2, 4-Hydroxybenzaldehyde, $\mathrm{R}=\mathrm{CHO}$ 5, 4-Hydroxybenzoic acid, $\mathrm{R}=\mathrm{COOH}$

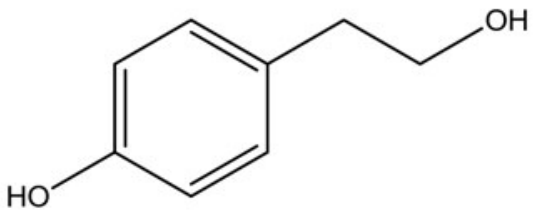

\section{4, Tyrosol}

Figure 1. Structure of nectriapyrone, 4-hydroxybenzaldehyde, p-cresol, tyrosol and 4-hydroxybenzoic acid (1-5).

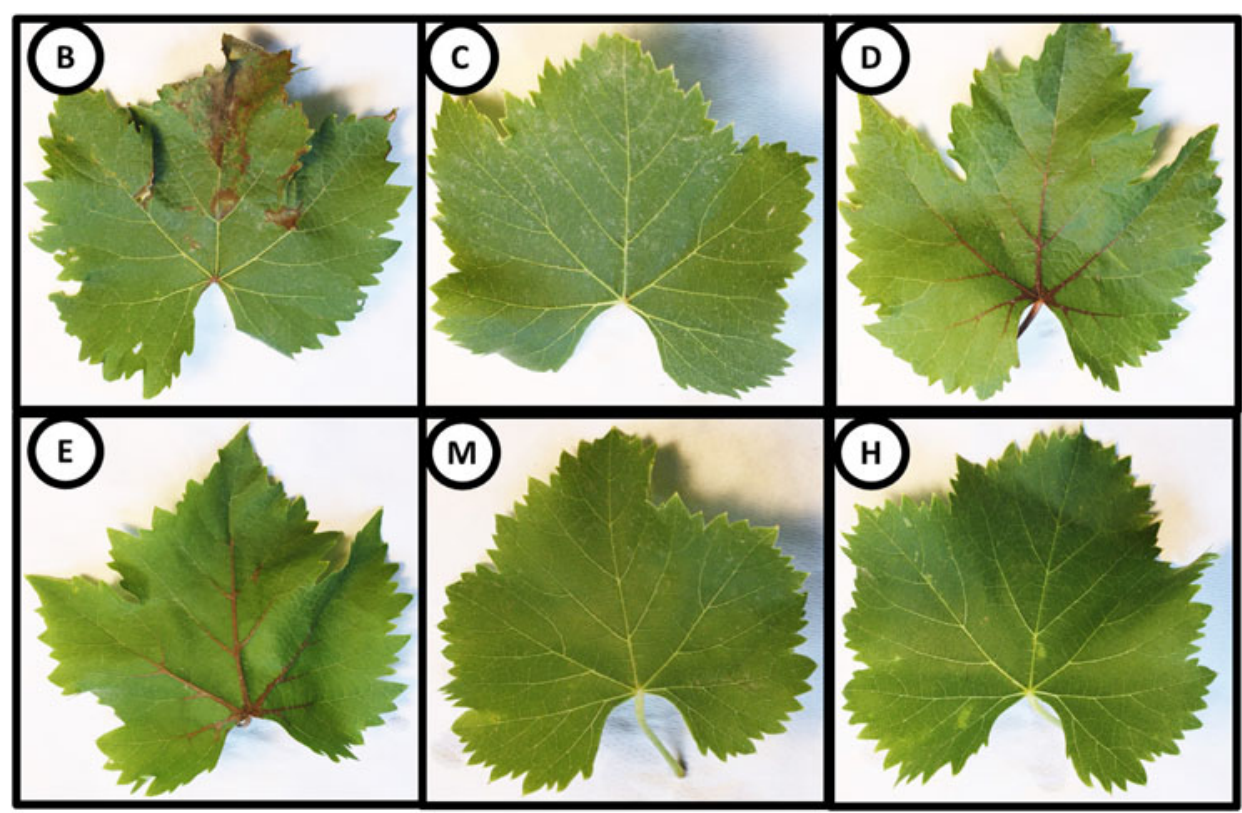

Figure 2. Symptoms caused by compounds 1-5 on leaves of Vitis vinifera in vitro at concentration of $1 \mathrm{mg} / \mathrm{ml}$ after $48 \mathrm{~h}$; (B) 4-hydroxybenzaldehyde (2); (C) p-cresol (3); (D) tyrosol; (E) 4-hydroxybenzoic acid (5); (H) distilled $\mathrm{H}_{2} \mathrm{O}$; (M) $10 \%$ methanol in distilled $\mathrm{H}_{2} \mathrm{O}$. 


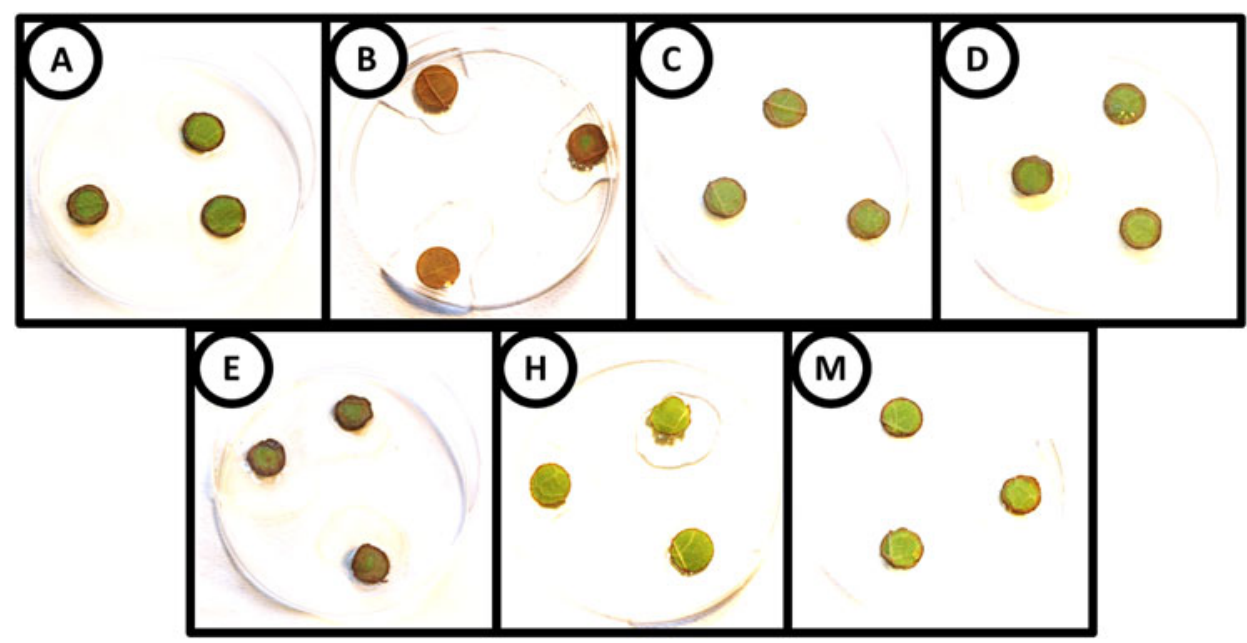

Figure 3. Symptoms caused by compounds $\mathbf{1 - 5}$ on disks of Vitis vinifera in vitro at concentration of $1 \mathrm{mg} / \mathrm{mL}$ after $48 \mathrm{~h}$; (A) nectriapyrone (1); (B) 4-hydroxybenzaldehyde (2); (C) p-cresol (3) (D) tyrosol (4); (E) 4-hydroxybenzoic acid (5); (H) distilled $\mathrm{H}_{2} \mathrm{O}$; (M) $10 \%$ methanol in distilled $\mathrm{H}_{2} \mathrm{O}$.

Table 1. Phytotoxic effect of Diaporthe eres metabolites (1-5) on grapevine leaf disks and leaf absorption assayed at $1 \mathrm{mg} / \mathrm{mL}^{\mathrm{a}}$ at $48 \mathrm{~h}$ from inoculation.

\begin{tabular}{lll}
\hline Compound & Disk & Leaf \\
\hline Nectriapyrone (1) & 2.7 & na \\
4-hydroxybenzaldehyde (2) & 5 & 2.7 \\
p-Cresol (3) & 3.3 & 4.3 \\
Tyrosol (4) & 2 & 0 \\
4-hydroxybenzoic acid (5) & 4.3 & 4.3 \\
Control (10\% MeOH in $\left.\mathrm{H}_{2} \mathrm{O}\right)$ & 1 & 0.3 \\
Distilled $\mathrm{H}_{2} \mathrm{O}$ & 1.3 & 0.7 \\
\hline
\end{tabular}

${ }^{a}$ Intensity of wilting, reddening of the veins and lamina deformation by a visual scale from 0 to $4(0=$ no effect; $4=$ severe symptoms.

na $=$ Not assayed.

Supplementary materials (Table S1 and Figures S1-S5); ESI-MS (+) m/z: $605\left[3 \mathrm{M}+\mathrm{Na}^{+}\right.$, $411[2 \mathrm{M}+\mathrm{Na}]^{+}, 389[2 \mathrm{M}+\mathrm{H}]^{+}, 233[\mathrm{M}+\mathrm{K}]^{+}, 217[\mathrm{M}+\mathrm{Na}]^{+}, 195[\mathrm{M}+\mathrm{H}]^{+}$.

4-Hydroxybenzaldehyde (2): ${ }^{1} \mathrm{H}$ NMR (CD $\left.\mathrm{OD}\right), \delta: 9.78(\mathrm{~s}, \mathrm{HCO}), 7.88(\mathrm{~d}, J=8.0 \mathrm{~Hz}$, $\mathrm{H}-2$ and $\mathrm{H}-6), 6.92,(\mathrm{~d}, J=8.0 \mathrm{~Hz}, \mathrm{H}-3$ and $\mathrm{H}-5)$; ESI/MS, $m / z: 123[\mathrm{M}+\mathrm{H}]^{+}$. These data are in agreement with the data previously reported (Venkatasubbaiah et al. 1991; Zhang et al. 2012). $p$-Cresol (3): ${ }^{1} \mathrm{H}$ NMR, $\delta: 7.04$ (d, $J=8.0 \mathrm{~Hz}, \mathrm{H}-3$ and H-5), $6.74(\mathrm{~d}, J=8.0 \mathrm{~Hz}, \mathrm{H}-2$ and H-6), 4.83 (br s, OH), $2.28 \mathrm{~s}, \mathrm{Me}) \operatorname{ESI} / \mathrm{MS}(+), \mathrm{m} / \mathrm{z}: 109$ $[\mathrm{M}+\mathrm{H}]^{+}$. These data are in agreement with the data previously reported (Kasthuraiah et al. 2004; Passmore et al. 2018).

Tyrosol (4): ${ }^{1} \mathrm{H}$ NMR, $\delta: 7.20(\mathrm{~d}, J=8.0 \mathrm{~Hz}, \mathrm{H}-2$ and H-6), $6.80(\mathrm{~d}, J=8.0 \mathrm{~Hz}, \mathrm{H}-3$ and $\mathrm{H}-5), 4.90(\mathrm{~s}, \mathrm{OH}), 3.80\left(\mathrm{t}, J=6.4 \mathrm{~Hz}, \mathrm{H}_{2}-8\right), 2.80\left(\mathrm{t}, J=6.4 \mathrm{~Hz}, \mathrm{H}_{2}-7\right)$. ESI/MS $(+), \mathrm{m} / \mathrm{z}: 299$ $[2 \mathrm{M}+\mathrm{Na}]^{+}, 139[\mathrm{M}+\mathrm{Na}]^{+}$. These data are in agreement with those previously reported (Kimura et al. 1973; Venkatasubbaiah et al. 1991; Capasso et al. 1992; Cimmino et al. 2017). 
4-Hydroxybenzoic acid (5): ${ }^{1} \mathrm{H}$ NMR $\left(\mathrm{CD}_{3} \mathrm{OD}\right), \delta: 7.9(\mathrm{~d}, J=8.0 \mathrm{~Hz}, \mathrm{H}-2$ and $\mathrm{H}-6)$, $6.8(\mathrm{~d}, J=8.0 \mathrm{~Hz}, \mathrm{H}-3$ and $\mathrm{H}-5)$. ESI/MS $(+), \mathrm{m} / \mathrm{z}: 139[\mathrm{M}+\mathrm{H}]^{+}$. These data are in agreement with the data previously reported (Zhang et al. 2012; Cimmino et al. 2017).

\subsection{Phytotoxic bioassays}

\subsubsection{Leaf absorption bioassay}

Grapevine leaves were cut and the petiole placed in a tube containing $1 \mathrm{~mL}$ of compound solution. The compound 1-5 were dissolved in $10 \%$ of $\mathrm{MeOH}$ in sterile distilled water (SDW) and tested at three different concentrations: $0.1,0.5$ and $1 \mathrm{mg} / \mathrm{mL}$. After $12 \mathrm{~h}$ or when the toxic solution was completely absorbed the leaf were moved to another tube containing SDW. The symptoms were visually assessed after $48 \mathrm{~h}$ using a 0 to four scale, where $0=$ no symptoms $4=$ severe symptom. SDW and $10 \% \mathrm{MeOH}$ SDW were used as negative control. The experiment was carried out in triplicate.

\subsubsection{Leaf disk bioassay}

$10 \mathrm{~mm}$ (diameter) disks of the lamina of grapevine leaves were obtained using a sharp corkborer. The leaf disks were immersed in $0.5 \mathrm{~mL}$ of compound solution. The compounds 1-5 were dissolved in $10 \%$ of $\mathrm{MeOH}$ in sterile distilled water (SDW) and tested at three different concentrations: $0.1,0.5$ and $1 \mathrm{mg} / \mathrm{mL}$. After $12 \mathrm{~h}$ or when the solution was completely absorbed the disks were moved to SDW. The symptoms were visually assessed after $6 \mathrm{~h}$, using a 0 to four scale, where $0=$ no symptoms $4=$ severe symptoms. SDW and $10 \%$ $\mathrm{MeOH}$ SDW were used as negative control. The experiment was carried out in triplicate.

\section{Conclusion}

Five metabolites were isolated from the culture filtrates of $D$. eres, a fungus isolated from symptomatic grapevine plants in a vineyard in Tuscany, and for the first time detected in Italy on grapevine. They were identified as 4-hydroxybenzaldehyde (2), 4hydroxybenzoic acid (5), nectriapyrone (1), p-cresol (3) and tyrosol (4) by comparing their physic and spectroscopic data with those of standard samples and those previously reported in literature. All, except 3, are already reported as phytotoxic metabolites produced by phytopathogenic fungi, while tyrosol and 4-hydroxybenzaldehyde are already known metabolites produced by other fungi involved in GTDs. $p$-Cresol is isolated for the first time as fungal phytotoxic microbial metabolites.

The role of these phytotoxic metabolites in the disease is not clear. In other GTDs phytotoxic metabolites are proved to contribute to symptom development in the crown, as in Eutypa lata, but we can also hypothesize that they have a role in fungal colonization of the tissue. Anyway, they are putative virulence factors available for the pathogenic fungi and deserve further investigation on plant tissue.

\section{Disclosure statement}

The authors declare that there are no conflict of interest. 


\section{Acknowledgements}

This manuscript was supported in part by academic grants from the Dipartimento di Scienze Chimiche, Università di Napoli Federico II, Italy. Antonio Evidente is associated with "Istituto di Chimica Biomolecolare del CNR", Pozzuoli, Italy.

\section{ORCID}

Pierlugi Reveglia (D) http://orcid.org/0000-0003-0588-2092

Andrea Pacetti (iD https://orcid.org/0000-0002-2114-4025

Marco Masi (DD http://orcid.org/0000-0003-0609-8902

Alessio Cimmino (D) http://orcid.org/0000-0002-1551-4237

Giuseppe Carella iD https://orcid.org/0000-0002-0297-0428

Laura Mugnai (iD http://orcid.org/0000-0002-2508-9764

Antonio Evidente (D) http://orcid.org/0000-0001-9110-1656

\section{References}

Albuquerque P, Casadevall A. 2012. Quorum sensing in fungi-a review. Med Mycol. 50(4): 337-345.

Andolfi A, Boari A, Evidente M, Cimmino A, Vurro M, Ash G, Evidente A. 2015. Gulypyrones A and $B$ and phomentrioloxins $B$ and $C$ produced by Diaporthe gulyae, a potential mycoherbicide for saffron thistle (Carthamus lanatus). J Nat Prod. 78(4):623-629.

Andolfi A, Maddau L, Cimmino A, Linaldeddu BT, Franceschini A, Serra S, Basso S, Melck D, Evidente A. 2012. Cyclobotryoxide, a phytotoxic metabolite produced by the plurivorous pathogen Neofusicoccum australe. J Nat Prod. 75(10):1785-1791.

Avent AG, Hanson JR, Truneh A. 1992. The biosynthesis of nectriapyrone and vermopyrone. Phytochemistry. 31(10):3447-3449.

Berger S, Braun S. 2004. 200 and more basic NMR experiments: A practical course. 1st ed. Weinheim: Wiley-VCH.

Capasso R, Cristinzio G, Evidente A, Scognamiglio F. 1992. Isolation, spectroscopy and selective phytotoxic effects of polyphenols from vegetable waste waters. Phytochemistry. 31(12): 4125-4128.

Cimmino A, Cinelli T, Masi M, Reveglia P, da Silva MA, Mugnai L, Michereff SJ, Surico G, Evidente A. 2017. Phytotoxic lipophilic metabolites produced by grapevine strains of Lasiodiplodia species in Brazil. J Agric Food Chem. 65(6):1102-1107.

Cimmino A, Masi M, Evidente M, Superchi S, Evidente A. 2015. Fungal phytotoxins with potential herbicidal activity: chemical and biological characterization. Nat Prod Rep. 32(12):1629-1653.

Cinelli T, Mondello V, Marchi G, Burruano S, Alves A, Mugnai L. 2016. First report of diaporthe eres associated with cane blight of grapevine (Vitis vinifera) in Italy. Plant Dis. 100(2):532-532.

Dissanayake AJ, Liu M, Zhang W, Chen Z, Udayanga D, Chukeatirote E, Li XH, Yan JY, Hyde KD. 2015. Morphological and molecular characterisation of Diaporthe species associated with grapevine trunk disease in China. Fungal Biol. 119(5):283-294.

Evidente A, Lanzetta R, Abouzeid MA, Corsaro MM, Mugnai L, Surico G. 1994. Foeniculoxin, a new phytotoxic geranylhydroquinone from Phomopsis foeniculi. Tetrahedron. 50(34): 10371-10378.

Evidente A, Punzo B, Andolfi A, Cimmino A, Melck D, Luque J. 2010. Lipophilic phytotoxins produced by Neofusicoccum parvum, a grapevine canker agent. Phytopathol Mediterr. 49:74-79.

Evidente A, Rodeva R, Andolfi A, Stoyanova Z, Perrone C, Motta A. 2011. Phytotoxic polyketides produced by Phomopsis foeniculi, a strain isolated from diseased Bulgarian fennel. Eur J Plant Pathol. 130(2):173-182.

Einhellig FA, Rasmussen JA. 1978. Synergistic inhibitory effects of vanillic and p-hydroxybenzoic acids on radish and grain sorghum. J Chem Ecol. 4(4):425-436. 
Guarnaccia V, Groenewald JZ, Woodhall J, Armengol J, Cinelli T, Eichmeier A, Ezra D, Fontaine F, Gramaje D, Gutierrez-Aguirregabiria A, et al. 2018. Diaporthe diversity and pathogenicity revealed from a broad survey of grapevine diseases in Europe. Persoonia. 40(1):135-153.

Guerin-Dubrana L, Fontaine F, Mugnai L. 2019. Grapevine trunk disease in European and Mediterranean vineyards: occurrence, distribution and associated disease-affecting cultural factors. Phytopathol Mediterr. 58:49-71.

Guo XW, Li K, Sun YN, Zhang LH, Hu XX, Xie HG. 2010. Allelopathic effects and identification of allelochemicals in grape root exudates. Acta Hortic Sinica. 37:861-868.

Kaliterna J, Miličević T, Cvjetković B. 2012. Grapevine trunk diseases associated with fungi from the Diaporthaceae family in Croatian vineyards. Arch Ind Hyg Toxicol. 63:471-479.

Kasthuraiah M, Kumar KA, Reddy CS. 2004. Facile synthesis, spectral characterization and antimicrobial activity of 6-substituted-2, 4, 8, 10-tetra-t-butyl dibenzo $[d, g][1,3,6,2]$ dioxathiaphosphocin 6-oxides. J Heterocycl Chem. 41(3):413-417.

Kimura Y, Tamura S. 1973. Isolation of I- $\beta$-phenyllactic acid and tyrosol as plant-growth regulators from Gloeosporium laeticolor. Agric Biol Chem. 37(12):2925-2925.

Lawrence DP, Travadon R, Baumgartner K. 2015. Diversity of Diaporthe species associated with wood cankers of fruit and nut crops in northern California. Mycologia. 107(5):926-940.

Masi M, Cimmino A, Reveglia P, Mugnai L, Surico G, Evidente A. 2018. Advances on fungal phytotoxins and their role in grapevine trunk diseases. J Agric Food Chem. 66(24):5948-5958.

Meepagala KM, Briscoe WE, Techen N, Johnson RD, Clausen BM, Duke SO. 2018. Isolation of a phytotoxic isocoumarin from Diaporthe eres-infected Hedera helix (English ivy) and synthesis of its phytotoxic analogs. Pest Manag Sci. 74(1):37-45.

Passmore IJ, Letertre MPM, Preston MD, Bianconi I, Harrison MA, Nasher F, Kaur H, Hong HA, Baines SD, Cutting SM, et al. 2018. Para-cresol production by Clostridium difficile affects microbial diversity and membrane integrity of Gram-negative bacteria. PLoS Pathog. 14(9): e1007191.

Reveglia P, Savocchia S, Billones-Baaijens R, Masi M, Evidente A. 2018. Spencertoxin and spencer acid, new phytotoxic derivatives of diacrylic acid and dipyridinbutan-1, 4-diol produced by Spencermartinsia viticola, a causal agent of grapevine Botryosphaeria dieback in Australia. Arabian J Chem. doi.org/10.1016/j.arabjc.2018.01.014.

Sessa L, Abreo E, Bettucci L, Lupo S. 2017. Diversity and virulence of Diaporthe species associated with wood disease symptoms in deciduous fruit trees in Uruguay. Phytopathol Mediterr. 56:431-444.

Tabacchi R, Fkyerat A, Poliart C, Dubin GM. 2000. Phytotoxins from fungi of esca of grapevine. Phytopathol Mediterr. 39:156-161.

Türkkan M, Andolfi A, Zonno MC, Erper I, Perrone C, Cimmino A, Vurro M, Evidente A. 2011. Phytotoxins produced by Pestalotiopsis guepinii, the causal agent of hazelnut twig blight. Phytopathol Mediterr. 50:154-158.

Úrbez-Torres JR, Peduto F, Smith RJ, Gubler WD. 2013. Phomopsis dieback: A grapevine trunk disease caused by Phomopsis viticola in California. Plant Dis. 97(12):1571-1579.

Venkatasubbaiah P, Sutton TB, Chilton WS. 1991. Effect of phytotoxins produced by Botryosphaeria obtusa, the cause of black rot of apple fruit and frogeye leaf spot. Phytopathology. 81(3):243-247.

Yu JQ, Matsui Y. 1994. Phytotoxic substances in root exudates of cucumber (Cucumis sativus L.). J Chem Ecol. 20(1):21-31.

Zhang H, Conte MM, Huang XC, Khalil Z, Capon RJ. 2012. A search for BACE inhibitors reveals new biosynthetically related pyrrolidones, furanones and pyrroles from a southern Australian marine sponge, lanthella sp. Org Biomol Chem. 10(13):2656-2663. 